\section{AB0462 UP TO 5-YEAR RETENTION OF ABATACEPT IN BELGIAN PATIENTS WITH MODERATE-TO-SEVERE RA: PROSPECTIVE DATA FROM THE REAL-WORLD ACTION STUDY}

R. Westhovens ${ }^{1}$, S.E. Connolly ${ }^{2}$, J. Margaux ${ }^{3}$, M. Vanden Berghe ${ }^{4}$, M. Maertens ${ }^{5}$ M. Van Den Berghe ${ }^{6}$, Y. Elbez ${ }^{7}$, M. Chartier ${ }^{8}$, F. Baeke ${ }^{9}$, S. Robert ${ }^{9}$, M. Malaise $^{10}$. ${ }^{1}$ UZ KU Leuven, Leuven, Belgium; ${ }^{2}$ Bristol-Myers Squibb, Princeton, USA; ${ }^{3}$ Hôpital Erasme, ULB, Brussels; ${ }^{4}$ Grand Hôpital de Charleroi, Charleroi; ${ }^{5}$ AZ Damiaan, Oostende; ${ }^{6}$ ASZ Aalst, Wetteren, Belgium; ${ }^{7}$ Excelya, Boulogne-Billancourt, ${ }^{8}$ Bristol-Myers Squibb, Rueil-Malmaison, France; ${ }^{9}$ Bristol-Myers Squibb, BraineL'Alleud; ${ }^{10} \mathrm{CHU}$ Sart Tilman, Liège, Belgium

Background: With its specific mechanism of action, abatacept (ABA) has shown good efficacy, acceptable safety and is well tolerated in patients (pts) with RA in randomised clinical studies. ${ }^{1,2}$ In a chronic disease such as RA, the long-term efficacy and safety of treatment are crucial and require validation in a real-world setting.

Objectives: To explore long-term safety and retention in pts with RA treated with IV ABA in routine clinical practice in the Belgian cohort of the AbataCepT In rOutiNe clinical practice (ACTION) study.

Methods: ACTION is a noninterventional, multicentre, prospective, longitudinal study of pts (aged $>18$ years) with established active moderate-to-severe RA, who initiated IV ABA in routine care. ${ }^{3}$ In Belgium, reimbursement criteria require failure with 2 conventional synthetic DMARDs and DAS28 (CRP) $>3.7$. The primary study objective was retention rate estimated using the Kaplan-Meier method.

Results: Overall, 135 Belgian pts from 16 sites (6 [4.4\%] first-line biological and 129 [95.6\%] second or further line) were enrolled between October 2010 and December 2012. Of these, 131 were evaluable for effectiveness analysis. Pts had a mean (SD) disease duration of 10.5 (9.7) yrs and were at high risk of disease progression: $25.4 \%$ of the evaluable pts had erosions $(n / n=33 / 130), 71.6 \%$ were anti-cyclic citrullinated peptide positive $(n / n=63 / 88)$ and $76.7 \%$ were $R F$ positive $(n / n=79 / 103)$. Overall, pts showed high disease activity at baseline according to mean (SD) DAS28 (ESR) 5.21 (1.02), DAS28 (CRP) 4.72 (1.09), CDAl 28.5 (11.1), SDAI 29.9 (11.9) and HAQ-DI score 1.23 (0.65). Patient and Physician Global Assessment of disease were mean (SD) 65.3 (20.95) and 58.02 (21.77), respectively. The overall retention rate $(95 \% \mathrm{Cl})$ was $76 \%(68.8,82.5), 64 \%$ $(54.8,71.5)$ and $34 \%(22.6,45.4)$ at 12,24 and 60 mths, respectively. When temporary discontinuations ( $>84$ days, $n=24$ ) were not included in the number of events, retention rates were $80 \%(72.0,85.9), 73 \%(64.0,79.4)$ and $51 \%(40.1$, 61.0 ) at 12,24 and 60 mths, respectively (Fig). Average DAS28 (CRP) before discontinuation and at restart was stable (3.37 [1.30] vs 3.73 [1.78], respectively $[n=12]$ ), suggesting that a temporary discontinuation of $>2$ consecutive ABA infusions does not seem to have a major clinical consequence. Pts who discontinued ABA due to lack of efficacy ( $n=37)$ had significantly shorter disease duration, higher CRP, higher number of prior DMARDs at baseline, mean DAS28 (CRP) of 3.61 (1.17) and DAS28 (ESR) of 4.66 (1.35) at discontinuation. Overall, ABA was generally well tolerated and no new safety signals were identified.

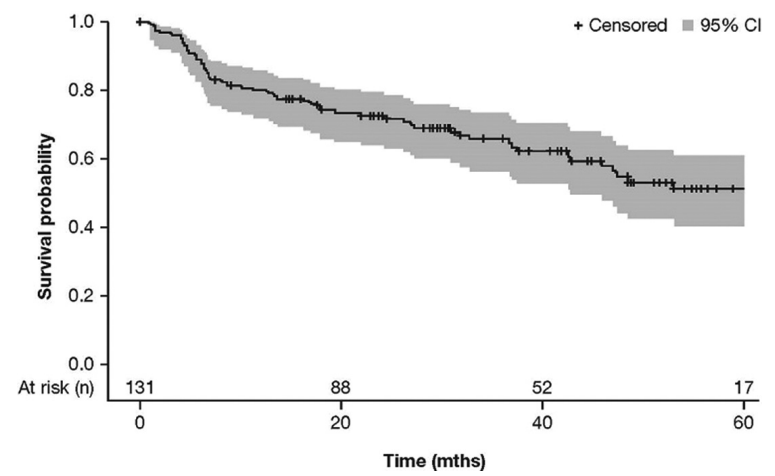

Abstract AB0462 - Figure 1. Treatment Retention Rate Over Time (Mths) in Study Population Evaluable for Effectiveness.

Conclusions: These real-world data demonstrate an acceptable safety profile for abatacept in Belgian pts with a stable retention rate of up to 5 years in a difficultto-treat population. A temporary discontinuation also seems feasible.

\section{REFERENCES:}

[1] Westhovens R, et al. Clin Exp Rheumatol 2014;32:553-62.

[2] Genovese MC, et al. J Rheumatol 2012;39:1546-54.

[3] Nüßlein HG, et al. Clin Exp Rheumatol 2016;34:489-99.
Disclosure of Interest: R. Westhovens Grant/research support from: BristolMyers Squibb, Roche, Janssen, Consultant for: Celltrion, Galapagos-Gilead, S Connolly Shareholder of: Bristol-Myers Squibb, Employee of: Bristol-Myers Squibb, J. Margaux: None declared, M. Vanden Berghe: None declared, M. Maertens Grant/research support from: Roche, Pfizer, M. Van Den Berghe: None declared, Y. Elbez: None declared, M. Chartier Employee of: Bristol-Myers Squibb, F. Baeke Shareholder of: Bristol-Myers Squibb, Employee of: BristolMyers Squibb, S. Robert Employee of: Bristol-Myers Squibb, M. Malaise: None declared

DOI: 10.1136/annrheumdis-2018-eular.1647

\section{AB0463 A REVIEW OF THE OUTCOMES OF WOMEN WITH RHEUMATOID ARTHRITIS (RA) TREATED WITH BIOLOGIC AGENTS ATTENDING THE SHEFFIELD COMBINED OBSTETRICS AND RHEUMATOLOGY CLINIC 2002 TO 2013}

R. Smith $^{1}$, R. Kilding ${ }^{1}$, K.-P. Kuet ${ }^{1}$, F. Fairlie ${ }^{2}$, R. Jokhi ${ }^{2}$, T. Bonnett ${ }^{2}$, M. Smith ${ }^{2}$ M. Akil ${ }^{1} .{ }^{1}$ Rheumatology Department, ${ }^{2}$ Obstetrics and Gynaecology, Royal Hallamshire Hospital, Sheffield, UK

Background: Women with RA have increased risk of complications including preeclampsia, low birth weight babies and Caesarean sections compared with unaffected women. ${ }^{1}$ Higher levels of disease activity have a negative influence on birth weight. ${ }^{2}$ More women are being treated with biologic agents, and there is growing evidence for their safe use in pregnancy. ${ }^{3}$

Objectives: To assess disease activity during pregnancy, and to review foetal and maternal outcomes.

Methods: Retrospective review of case notes.

Results: Between 2002 and 2013, 17 women with RA treated with biologic agents attended the combined clinic. 13 were treated with Etanercept, 2 Adalimu mab, 1 Tocilizumab and 1 Rituximab. 13 were in combination with disease modify ing anti-rheumatic agents (DMARDs). There were 17 pregnancies. 2 women stopped their biologic prior to conception; 14 stopped on confirmation of preg nancy. 12 women had active disease during pregnancy. All had some form of steroid treatment, 3 had a DMARD introduced, and 1 restarted Etanercept at 20 weeks.

There were 14 live births and 2 first trimester miscarriages. There was 1 elective Caesarean section, 7 spontaneous deliveries, and 5 inductions, 3 of which proceeded to Caesarean. Data is missing for 2 women. 10 babies were born at term 3 were pre-term and data is missing for 2.2 babies weighed less than $2500 \mathrm{~g}$ and 2 more than $4500 \mathrm{~g}$. Data is missing for 3 babies. The low birth weight babies were also pre-term, had cardiac abnormalities and required admission to the neonatal unit. Both mothers had stopped Etanercept at confirmation of pregnancy. Both flared during pregnancy.

6 women developed complications: hypertension, diabetes, proteinuria, cervical incompetence, and hypothyroidism. 4 of these had active disease during thei pregnancies. 2 babies had intrauterine growth restriction, 2 cardiac abnormalities and 1 macrosomia. All had mothers who flared during pregnancy.

Conclusions: Our group of patients is small, but the outcomes are comparable to those of women with RA. There is no discernible increase in adverse events due to biologic use. In 2014 product recommendations were to stop biologics prior to conception. ${ }^{4}$ Since 2016 the British Society for Rheumatology has advised that Etanercept and Adalimumab are compatible with use in the first and second trimesters. Tocilizumab and Rituximab should still be stopped prior to conception. ${ }^{3}$ Local practice has changed to reflect this guidance, and the next step in this project is to review the data from more recent pregnancies to determine whether more prolonged use of biologics improves disease control and in turn foetal and maternal outcomes.

\section{REFERENCES}

[1] Lin $\mathrm{H}$, et al. Increased risk of adverse pregnancy outcomes in women with rheumatoid arthritis. Annals of the Rheumatic Diseases 2010;69(4):715-7.

[2] de Man $Y$, et al. Association of higher rheumatoid arthritis disease activity during pregnancy with lower birth weight. Arthritis \& Rheumatism 60:31963206.

[3] Flint J, et al. BSR and BHPR guideline on prescribing drugs in pregnancy and breastfeeding_-Part I. Rheumatology. 2016;55(9):1693-1697.

[4] Hyrich K, et al. Biologic therapies and pregnancy: the story so far. Rheumatology 2014;53(8):1377-1385.

Disclosure of Interest: None declared

DOI: 10.1136/annrheumdis-2018-eular.2096 


\section{$\mathrm{AB} 0464$}

'REAL LIFE' BIOLOGICAL DRUG TAPERING RESULTS IN FEW FLARES OF DISEASE AND SIGNIFICANT COST SAVINGS

\section{S. Batool ${ }^{1}$, M. Perry ${ }^{1}$, D. Russell ${ }^{2} .{ }^{1}$ Rheumatology; ${ }^{2}$ Pharmacist, NHS, Glasgow} UK

Background: The treatment of rheumatic diseases has been revolutionised in the biologic era. Remission and low disease activity are realistic targets. Several trials have suggested that dose reduction is achievable without loss of clinical effect. However, 'real life' response data is still lacking.

Objectives:

- To increase interval dose of biologic drugs in a standard rheumatology clinic setting

- To assess the clinical response and determine potential cost savings

Methods: Patients were identified by database interrogation and hospital prescription record, from a regional population of 400000 over a 2 year period. All rheumatic conditions treated with anti-TNF and IL-6 blockers were potentially accepted for tapering. Those with low disease activity scores (RA and PsA DAS $<2.1$, AS BASDAI <4.1) for $>1$ year were screened and invited to consider dose reduction following discussion in a clinic.

Results: 154 biologic patients were screened and 97 contacted to consider dose tapering. Of these, 40 patients agreed to participate in biologic dose reduction. Demographics: Mean age 51 years, 18 male patients and 22 females, concomitant MTX use in 49\%. Diagnosis: RA-24, PsA -9, AS- 7. Drugs tapered included Adalimumab (28), Etanercept (5), Golimumab (5) and Tocilizumab (2). 8 patients flared during the programe and response was recaptured in 2 patients after increasing dose. 32 patients were successfully maintained on reduced dose with no requirement to date to increase dosing frequency. Biologic drug was completely withdrawn in 1 patient and 2 patients were commenced on reduced dose of DMARD. Prior to dose reduction mean DAS was 1.91 and mean BASDAI was 2.45. Low disease activity scores were recorded (mean DAS 2.1, mean BASDAI 2.6) post dose reduction (although incomplete data capture). Estimated cost savings are between 170,000 EUR and 340000 EUR for the 2 years.

Conclusions: Successful tapering of biologic drugs can be achieved and sustained in non-trial settings for patients with low disease activity. Significant cost savings have been confirmed with likelihood of recurrent savings over future years.

\section{REFERENCE:}

[1] Edwards C, Fautrel B, Schulze-Koops H, Huizinga T, Kruger K. Dosing down with biologic therapies: a systematic review and clinicians' perspective 2018.

Acknowledgements: Ms Vandana Raghuvir Medical student at Glasgow University

Disclosure of Interest: None declared

DOI: 10.1136/annrheumdis-2018-eular.5600

\section{AB0465 SAFETY AND DURATION OF BIOLOGIC TREATMENT IN ELDERLY PATIENTS WITH RHEUMATOID ARTHRITIS}

S. Garrote Corral, A. Garcia Fernandez, P. Moran Alvarez, F.J. Bachiller Corral. Rheumatology, Hospital Ramon y Cajal, Madrid, Spain

Background: Several differences may be expected between young and elderly patients with rheumatoid arthritis (RA), safety and efficacy results are variable in the different previous studies. ${ }^{1,2}$

Objectives: To compare the duration and safety of biological treatment in patients with RA depending on the age of onset of therapy, in a Spanish tertiary centre.

Methods: We conducted a retrospective observational study of patients with a diagnosis of RA who were receiving biologic treatment. They were diagnosed between February 1980 and February 2017, on the basis of criteria ACR/EULAR 2010 or 1987 ACR criteria. The information was obtained from review of medical records. We divided the patients in two groups according to age of the onset of treatment: elderly group ( $\geq 65$ years) and young group ( $<65$ years).

Results: 140 patients were included. At the beginning of the treatment 89 were under 65 years and 51 older (65-74 years: 28 patients, $>75$ years: 23 ). The average duration of the disease from diagnosis until the beginning of the biological treatment was $103 \pm 91$ months in young patients and $142,86 \pm 109,5$ months in elderly patients $(p: 0,023)$. We detected no differences between both groups at baseline characteristics, except for comorbidities and sex. DAS28PCR prior to biologic therapy was $5.20 \pm 1.44$ in young patients and $5.14 \pm 0813$ in elderly ( $p: 0,37$ ).
Duration of the treatment was similar in both groups. Suspension of biologic treatment occurred in 50 young patients (56\%) and 30 elderly patients (58\%) (table 1). The causes are detailed in table 2 . Adverse effects were more frequent in the elderly but without statistical significance. There were 9 cases of cancer in elderly patients $(17.3 \%$ ) and 4 cases in young patients $(4.6 \%)$ p: 0013 . The average diag nosis of cancer prior to the introduction of biologic treatment was $5.8 \pm 7.1$ years.

\begin{tabular}{lccc} 
Abstract AB0465 - Table 1 & $\begin{array}{c}\text { Young patients } \\
(<65 \text { years }) \\
\mathrm{n}=89\end{array}$ & $\begin{array}{c}\text { Elderly patients } \\
(\geq 65 \text { years })\end{array}$ & $\mathrm{p}=51$ \\
\hline Age diagnostic AR (years) & $42,87( \pm 11.34)$ & $62( \pm 10.65)$ & 0.42 \\
Age biological treatment & $51,39( \pm 10.32)$ & $73.8( \pm 5.30)$ & $<0.001^{*}$ \\
(years) & $74(83.1 \%)$ & $35(68,65 \%)$ & $0.04^{*}$ \\
Sex: female & 0 & $4(8.3 \%)$ & $0.006^{*}$ \\
Comorbidities & $2(2.2 \%)$ & $5(9.8 \%)$ & $0,048^{*}$ \\
Heart failure & $16(18 \%)$ & $11(21 \%)$ & $0,013^{*}$ \\
Renal failure & $31(34.8 \%)$ & $10(19.6 \%)$ & \\
Type biological & $27(30.3 \%)$ & $10(19.6 \%)$ & \\
Infliximab & $3(3.4 \%)$ & $2(3.9 \%)$ & \\
Adalimumab & $4(4.5 \%)$ & $2(3.9 \%)$ & \\
Etanercept & $7(7.9 \%)$ & $8(15.7 \%)$ & \\
Certolizumab & 0 & $6(11.8 \%)$ & \\
Abatacept & & & \\
Tocilizumab & $39.98( \pm 41,04)$ & $46,31( \pm 33.28)$ & 0.095 \\
Rituximab & $13(14.6 \%)$ & $12(21.56 \%)$ & 0.7 \\
Duration treatment(months) & $6(46 \%)$ & $6(54 \%)$ & \\
Adverse events & 0 & $1(9.1 \%)$ & \\
Serious/recurrentinfection & $1(7.1 \%)$ & $1(9.1 \%)$ & \\
Active tumour & $3(23 \%)$ & 0 & \\
Cytopenias & $2(15 \%)$ & $1(9.1 \%)$ & \\
Skin lesions & & & \\
Gastrointestinal symptoms & & & \\
\hline
\end{tabular}

Abstract AB0465 - Table 2

\begin{tabular}{lccc}
\hline & $\begin{array}{c}\text { Young } \\
\text { patients }\end{array}$ & $\begin{array}{c}\text { Elderly } \\
\text { patients }\end{array}$ & $\mathrm{p}$ \\
\hline $\begin{array}{l}\text { Lack of efficacy } \\
\text { (<6 months) }\end{array}$ & $10(20 \%)$ & 0 & $0.015^{\star}$ \\
$\begin{array}{l}\text { Lack of efficacy } \\
\text { ( }>6 \text { months) }\end{array}$ & $22(44 \%)$ & $10(33 \%)$ & 0.55 \\
$\begin{array}{l}\text { Adverse event } \\
\text { Remission }\end{array}$ & $8(16 \%)$ & $8(26.6 \%)$ & 0.16 \\
\hline
\end{tabular}

Conclusions: Our study corroborate that biologic treatment has similar duration and safety in elderly and young patient. ${ }^{1,2}$

\section{REFERENCES}

[1] Ishchenko A, Lories RJ. Safety and Efficacy of Biological Disease-Modifying Antirheumatic Drugs in Older Rheumatoid Arthritis Patients: Staying the Distance; Drugs Aging 2016;33:387-398.

[2] Lahaye C, et al. Overview of biologic treatments in the elderly. Joint Bone Spine 2015;82(2015):154-160

Disclosure of Interest: None declared

DOI: 10.1136/annrheumdis-2018-eular.7451

\section{AB0466 SAFETY OF RITUXIMAB IN PATIENTS WITH RHEUMATOID ARTHRITIS. ELEVEN-YEAR FOLLOW-UP OBSERVATIONAL STUDY}

S.D.L.C. Rodriguez García, R. Castellanos-Moreira, M.V. Hernandez-Miguel, A. Cuervo, O. Camacho, V. Ruiz-Esquide, J. Ramirez, J.D. Cañete, J. Gomez Puerta, R. Sanmartí. Rheumatology, Hospital Clinic de Barcelona, Barcelona, Spain

Background: Rituximab (RTX) is a chimeric monoclonal antibody approved for the treatment of active rheumatoid arthritis (RA) in patients who failed to respond to tumour necrosis factor inhibitors (TNFi). Due to its effect on induction of $B$ cell depletion, the administration of multiple cycles can lead to a decrease in immunoglobulins (Ig) which may increase the risk of infection.

Objectives: To assess the long-term safety of RTX in patients with RA and to evaluate factors associated with the presence of infections. 